\title{
Learned helplessness: Now you see it, now you don't
}

\author{
DENNIS C. COGAN and GARY L. FRYE \\ Texas Tech University, Lubbock, Texas 79409
}

\begin{abstract}
Eleven active avoidance tests of "learned helplessness" were run on rats to determine the feasibility of using the paradigm as an analog of depression. In two experiments, the avoidance task required a barpress response. In the remaining experiments, a one- or two-way shuttle response was required. Numbers of trials, shock level, shock time, and several other aspects were varied. In seven cases, the "helpless" animals took marginally longer to learn. In four cases, the reverse was true. The differences between groups did not reach statistical significance in any of the 11 experiments. The authors concluded that "learned helplessness," in rats, is too sensitive to minor procedural changes to constitute a good paradigm for the study of depression.
\end{abstract}

The importance of the development and use of animal models of debilitating human disorders is unquestioned (Serban, Pichot, Freedman, \& Kittay, 1976). The use of such models in the study of physical diseases (e.g., cancer) is well known, successful, and accepted. However, the development and use of animal models of psychopathological problems has not progressed very far until quite recently (Keehn, 1979; Seligman, 1977).

Seligman (Miller, Rosellini, \& Seligman, 1977) has offered an animal model for depression in humans, based on his "learned helplessness" theory. The basic experimental paradigm involves exposing a group of subjects to some noxious event (usually shock in animals, insoluble problems in humans) that cannot be avoided, no matter what response or responses the subjects make. Later, these subjects and control subjects who have not been exposed to the unavoidable noxious event are trained on some avoidance task. In most instances, the subjects exposed to the unavoidable noxious event are inferior to the control subjects in performing the subsequent avoidance task. Seligman and his co-workers attribute this phenomenon to the subjects' having learned to be "helpless" during the exposure to the unavoidable noxious event (Klein \& Seligman, 1976; Maier, 1970; Seligman \& Beagley, 1975; Seward \& Humphrey, 1967). This "learned helplessness" results in interference with later learning, particularly of avoidance behaviors. These phenomena have been reported in a variety of species, including humans (Seligman \& Beagley, 1975).

This research was supported by grants from the Texas Tech University Institute for Research. Reprint requests should be sent to the first author, Psychology Department, Texas Tech University, Lubbock, Texas 79409.
The fact that very similar impairment in later learning is found in humans having been exposed to insoluble problems (Klein \& Seligman, 1976) and the fact that these human subjects often report feelings of depression and lowered self-worth (Hiroto \& Seligman, 1975; Miller \& Seligman, 1975) has led to the proposal that the "learned helplessness" effect is an analog for depression. While many problems with the theory of learned helplessness and its relationship to depression remain (see Journal of Abnormal Psychology, July 1979), the possibility that the phenomenon may replicate, in animals, some aspects of depression is still valid and has yet to be examined thoroughly.

It was our purpose, in beginning the series of investigations reported here, to attempt to verify the validity of the learned helplessness effect as an analog of depression using rats. Since several investigators had reported that helplessness is more difficult to demonstrate in rats (Beagley \& Beagley, 1978; Maier, Albin, \& Testa, 1973; Seligman \& Beagley, 1975) and still others had reported being unable to obtain the effect at all (Beatty, 1979; Bracewell \& Black, 1974), we felt a reasonable first step should be an evaluation of the basic paradigm itself. We set about doing this by using the same parameters that Seligman and Beagley (1975) had reported using successfully. Although our outcomes were in the direction we had expected, we were unimpressed with the definitiveness of our results (see Table 1) and determined to try again with minor modifications of the procedure designed to strengthen the effect (we hoped). Again, we were singularly unimpressed with the results, although they were in the "right" direction. We planned a further experiment with modifications, and so on, through 2 years and 11 attempts to find a procedure that would reliably produce learned helplessness. 
Table 1

Mean Time to the First (R1) and Second (R2) Avoidance Responses for all 11 Experiments

\begin{tabular}{|c|c|c|c|c|c|c|}
\hline \multirow{2}{*}{$\begin{array}{c}\text { Experi- } \\
\text { ment }\end{array}$} & \multicolumn{2}{|c|}{ Signaled Shock } & \multicolumn{2}{|c|}{ Unsignaled Shock } & \multicolumn{2}{|c|}{ Restrained } \\
\hline & $\mathrm{R} 1$ & $\mathrm{R} 2$ & $\mathrm{R} 1$ & $\mathrm{R} 2$ & $\mathrm{R} 1$ & $\mathrm{R} 2$ \\
\hline 1 & 32.20 & & 33.86 & & 30.98 & \\
\hline 2 & 42.51 & & 43.09 & & 40.63 & \\
\hline 3 & 13.46 & 18.41 & 8.98 & 11.00 & 8.88 & 10.96 \\
\hline 4 & 14.89 & 17.60 & 22.31 & 25.20 & 18.08 & 20.65 \\
\hline 5 & 14.14 & 18.36 & 11.14 & 15.63 & & \\
\hline 6 & 26.97 & 30.68 & 18.37 & 20.91 & & \\
\hline $7 \mathrm{H}$ & 23.62 & 27.11 & 11.77 & 13.13 & & \\
\hline $7 \mathrm{~L}$ & 17.72 & 19.14 & 20.71 & 22.87 & & \\
\hline 8 & & & 26.16 & 27.93 & 25.98 & 28.22 \\
\hline 9 & & & 24.41 & 29.20 & 28.76 & 29.31 \\
\hline 10 & & & 20.28 & 23.31 & 17.47 & 9.23 \\
\hline 11 & & & & 25.62 & & 13.46 \\
\hline
\end{tabular}

\section{METHOD}

\section{Subjects}

In each of the 11 experiments, male rats of the SpragueDawley strain were used, all between 90 and 180 days of age.

\section{Apparatus}

For Experiments 1 and 2, the unavoidable shock chambers were three $30 \times 19 \times 20.5 \mathrm{~cm}$ boxes made of sound-deadening ceiling tiles and painted black inside and out. Shock was delivered through a stainless steel safety pin electrode pinned between the subjects' shoulder blades. For the remainder of the experiments, the unavoidable shock was delivered while the animal was in passive restraint. In these later experiments, the shock was delivered through an electrode attached to the subject's tail.

Avoidance testing was done in a BRS operant chamber, using a BRS shocker, for Experiments 1 and 2. For the remaining experiments, avoidance testing was done in a Hunter shuttle-avoidance chamber.

\section{Procedure}

General. While the details of the experiments differed somewhat according to what we felt would produce a stronger effect (see below), there were practices common to several of them. All subjects were on ad-lib food and water. The signaled shock control groups (Experiments 1-7) received their shocks yoked to the sequence and duration of the shocks given to one of the unsignaled subjects. Unless otherwise noted, the shocked animals received 60 shocks of $5 \mathrm{sec}$ duration at $1.0 \mathrm{~mA}$, in an 80 -min session. Avoidance testing was done $24 \mathrm{~h}$ after the unavoidable shock experience except as noted.

Specific. Experiment 1. The subjects received 60 30-sec shocks in the 80-min session. Signaled shock subjects were given a light signal $5 \mathrm{sec}$ prior to shock onset. Avoidance testing was done in the operant chamber requiring an FR 1 for avoidance on Trials 1-5 and FR 2 thereafter. There were six subjects per group, signaled, unsignaled, and control.

Experiment 2. The procedures were essentially the same as those in Experiment 1, with the exception that the signaled shock group received both a tone and a light signal and an FR 2 response was required for successful avoidance from Trial 1. Eight subjects were run per group, signaled, unsignaled, and control.

Experiment 3. Maier et al. (1973) suggested that the shuttleavoidance response might yield stronger evidence for the learned helplessness effect than the barpress response. We determined to try this. The subjects were shocked 50 times $(1.0 \mathrm{~mA})$, with each shock of $5 \mathrm{sec}$ duration, while in passive restraints designed to restrict movement that might reduce the effectiveness of the shock. Each subject was given 30 one-way avoidance training trials (30-sec intertrial interval) $24 \mathrm{~h}$ after the unavoidable shock experience. The 10-mm-high barrier was electrified to prevent the subject's avoiding by clinging to it. Three subjects were run in each of three groups, signaled, unsignaled, and control.

Experiment 4. This was run in the same fashion as Experiment 3, with the exception that the avoidance response required was of the two-way variety. There were, again, three subjects in each of three groups, signaled, unsignaled, and control.

Experiment 5. This was a replication of Experiment 4 with no changes. There were three subjects in the three groups.

Experiment 6. This experiment was essentially the same as Experiment 5, except that new, presumably less noxious restraints were used. There were two subjects per group, signaled, unsignaled, and control.

Experiment 7. We thought that the shock level during the helplessness phase might be important. The subjects received unavoidable shocks at either $.8 \mathrm{~mA}$ or $.4 \mathrm{~mA}$, and then all subjects were tested at $.6 \mathrm{~mA}$ during avoidance training. There were two subjects in each of four groups (no nonshock control groups were included).

Experiment 8. We had been using naive rats bred in our own laboratory and thought, perhaps, the strain had become atypical through inbreeding. This experiment used the same procedures as Experiment 3, with the exception that the animals were purchased from the Holtzman Company, Madison, Wisconsin. There were nine subjects in each of the two groups. No signaled shock subjects were run.

Experiment 9. The results of Experiment 8 were encouraging. We thought that decreasing the time between training and avoidance testing might heighten the effect. The procedures were identical to those of Experiment 8, except that the time between the unavoidable shock manipulation and the avoidance testing was reduced to $1 \mathrm{~h}$. Six subjects were run in each of two groups. The subjects were from our own colony.

Experiment 10. We felt that the electrified barrier might be retarding the learning of the controls in the two-way avoidance. The procedures were the same as those in Experiment 9, except the electrified barrier was replaced by a wall with a $7-\mathrm{cm}$-diam hole cut in the center. Six subjects were run in each of the two groups, unsignaled and restrained.

Experiment 11. We were encouraged by the large differences observed in latencies to the second response (see Table 1) until we observed the unsignaled shock animals clinging to the barrier wall (an obvious avoidance response) with their hind feet in the hole and their tails elevated from the grid. We decided to try a low $(20-\mathrm{cm})$ narrow barrier to keep the subjects from using it as a way of avoiding shock. The subjects were run the same way as in Experiment 10, with a low barrier. Six subjects were run in each of two groups, unsignaled and restrained.

\section{RESULTS AND DISCUSSION}

A summary of the major findings is shown in Table 1. The data presented are the mean times to respond (first and second responses when appropriate) during the avoidance conditioning trials. Note that in 7 of 11 cases [Experiments 1, 2, 4, 7 (low shock), 8,10 , and 11] the results were in the direction predicted by the theory of learned helplessness.

The analyses of variance (groups by trials) of each experiment indicated that the only significant effect in any of the experiments was the effect of trials. That is, in all experiments, all groups showed significant avoidance learning, but there were no significant 
main effects for groups or Groups by Trials interactions in any of the 11 experiments. A chi-square analysis of the frequency of validating vs. nonvalidating outcomes (11 vs. 7 , respectively) was nonsignificant as well $\left[\chi^{2}(1)=.81\right]$. We concluded that the null hypothesis had to be accepted.

While the power of the statistical tests was low in several cases due to small sample sizes, this was not true of all the experiments. Thus, the failure to observe a significant effect in any of the experiments cannot be attributed solely to the inadequacies of the designs. More critically, it seems to us that, even if learned helplessness is a viable phenomenon with very small effects, over 11 experiments some trend toward supporting the theory should emerge. Clearly, this did not happen in our series of experiments, even when we most painstakingly replicated previously successful procedures.

Beatty (1979), in two experiments, found no evidence for a helplessness effect. Several other investigators (Brookshire, Littleman, \& Stewart, 1961, Experiment 1; deToledo \& Black, 1967) have, as did we in several instances, found unavoidable shock to facilitate later avoidance learning. Seligman and Beagley (1975) have implied that these contradictory findings may be attributed to small procedural differences from experiment to experiment. In our opinion, any effect that lacks the robustness to overcome such small discrepancies may well be an artifact of the specific procedures that yield it. On the basis of the evidence reported here, we seem inescapably drawn to the depressing conclusion that learned helplessness, in the rat, is not a reliable enough phenomenon to be considered an analog of depression.

\section{REFERENCES}

Beagley, C. H., \& Beagley, W. K. Alleviation of learned helplessness following septal lesions in rats. Physiological Psychology, 1978, 6, 241-244.

BEATTY, W. W. Failure to observe learned helplessness in rats exposed to inescapable footshock. Bulletin of the Psychonomic Society, 1979, 13, 272-273.
Bracewell, R. J., \& Black, A. H. The effects of restraint and noncontingent preshock on subsequent escape learning in the rat. Learning and Motivation, 1974, 5, 53-69.

Brookshire, K. H., Littleman, R. A., \& Stewart, C. N. Residue of shock trauma in the white rat: A three factor theory. Psychological Monographs, 1961, 75(10, Whole No. 514).

DETOLEDo, L., \& Black, A. Effects of preshock on subsequent avoidance conditioning. Journal of Comparative and Physiological Psychology, 1967, 63, 493-498.

Hiroto, D. S., \& Seligman, M. E. P. Generality of learned helplessness in man. Journal of Personality and Social Psychology, 1975, 31, 311-327.

KEEHN, J. D. Psychopathology in animal and man. In J. D. Keehn (Ed.), Psychopathology in animals: Research and clinical implications. New York: Academic Press, 1979.

Klein, D. C., \& Seligman, M. E. P. Reversal of performance deficits and perceptual deficits in learned helplessness and depression. Journal of Abnormal Psychology, 1976, 85, 11-26.

MAIER, S. F. Failure to escape traumatic shock: Incompatible skeletal motor responses or learned helplessness? Learning and Motivation, 1970, 1, 157-170.

Maier, S. F., Albin, R. W., \& Testa, T. Failure to learn to escape in rats previously exposed to inescapable shock depends on nature of escape response. Journal of Comparative and Physiological Psychology, 1973, 85, 581-592.

Miller, W. R., Rosellini, R. A., \& Seligman, M. E. P. Learned helplessness and depression. In J. D. Maser \& M. E. P. Seligman (Eds.), Psychopathology: Experimental models. San Francisco: Freeman, 1977.

Miller, W. R., \& Seligman, M. E. P. Depression and learned helplessness in man. Journal of Abnormal Psychology, 1975, 84, 228-238.

Seligman, M. E. P. Modeling psychopathology in the laboratory: History and rationale. In J. D. Maser \& M. E. P. Seligman (Eds.), Psychopathology: Experimental models. San Francisco: Freeman, 1977.

Seligman, M. E. P., \& Beagley, G. Learned helplessness in the rat. Journal of Comparative and Physiological Psychology, 1975, 88, 534-541.

Serban, G., Pichot, P., Freedman, A. F., \& Kittay, S. New perspectives in psychiatry: Relevance of the psychopathological animal model to the human. In G. Serban \& A. Kling (Eds.), Animal models in human psychobiology. New York: Plenum, 1976.

Seward, J., \& Humphrey, G. L. Avoidance learning as a function of pretraining in the cat. Journal of Comparative and Physiological Psychology, 1967, 63, 338-341.

(Received for publication May 22, 1981.) 